\title{
A recusa de Marx da teoria do valor
}

\author{
David Harvey
}

Trad.: Carine Botelho Previatti

USP

\section{revista}

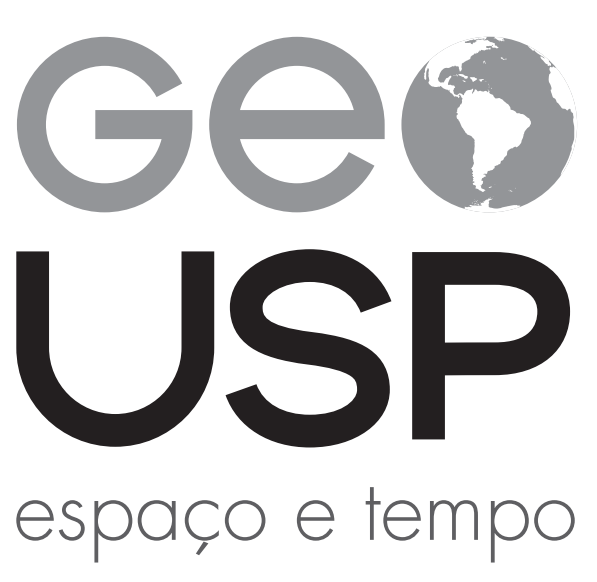

Volume $22 \cdot n^{\circ} 1(2018)$
Como citar este artigo:

HARVEY, D. A recusa de Marx da teoria do valor. Trad.: Carine Botelho Previatti. Geousp - Espaço e Tempo (Online), v. 22, n. 1, p. 257-264, mês. 2018. ISSN 2179-0892.

Disponível em: <http://www.revistas.usp.br/geousp/article/ view/145931>. doi: http://dx.doi.org/10.11606/issn.2179-0892. geousp.2018.145931.

\section{(c) (i) (5)}

Este artigo está licenciado sob a Creative Commons Attribution 4.0 License. 


\section{A recusa de Marx da teoria do valor}

David Harvey ${ }^{2}$

Trad.: Carine Botelho Previatti

\section{Resumo}

Neste artigo recente, ainda não publicado em livro, David Harvey compara a teoria do valor-trabalho de Ricardo e a teoria do valor adotada por Karl Marx, trazendo uma amostra das discussões de seu mais recente livro, Capital e a loucura da razão econômica. $\bigcirc$ autor discute as diferenças entre essas teorias e seus desdobramentos nos estudos marxistas atuais, concluindo que a forma valor dos estudos de Marx não pode ser considerada um "princípio imóvel e estável no mundo tumultuado do capital, mas uma métrica instável e em constante mudança", que se expressa nas "novas práticas de reprodução social e massivas transformações nas vontades, necessidades e desejos de toda uma população" pela inserção na vida cotidiana. Segundo o autor, isso demonstra que essa teoria está "muito além do que Ricardo tinha em mente e é igualmente distante daquela concepção de valor geralmente atribuída a Marx".

Palavras-chave: Teoria do valor-trabalho. Teoria do valor. Karl Marx. Ricardo. capital.

\section{Marx's Refusal of the Labour Theory of Value}

\section{Abstract}

In this recent article, not yet available by publishers, David Harvey does a comparison between the labour theory of value from Ricardo and the value theory from Karl Marx, bringing a sample of the discussions of his latest book Marx, Capital and the Madness of Economic Reason. The author thus discusses the differences between these theories and their unfoldings in the current Marxist studies, concluding that the value form from the Marx studies could not be considered as a "stable fulcrum in capital's churning world but a constantly changing and unstable metric", which is expressed through "by unfolding practices of social reproduction, and massive transformations in the wants, needs and desires of whole populations" through everyday life. That

1 Texto originalmente publicado em Harvey (2018).

2 As notas do autor são indicadas com NA. As da revisão, com NR, todas contribuições de Felipe Saluti Cardoso. 
demonstrates, according to the author, that this theory is "far beyond what Ricardo had in mind and equally far away from that conception of value usually attributed to Marx".

Keywords: Labour theory of value. Value theory. Karl Marx. Ricardo. Capital.

É amplamente admitido que Marx tenha adaptado a teoria do valor-trabalho de Ricardo na concepção fundamental de seus estudos de acumulação de capital. Visto que a teoria do valor-trabalho tem sido geralmente desacreditada, passou a ser estabelecido, de forma até mesmo autoritária, que as teorias de Marx são inúteis. Mas em nenhum lugar, de fato, Marx declarou sua lealdade à teoria do valor-trabalho. Essa teoria pertencia a Ricardo, que reconheceu que ela era profundamente problemática, mesmo insistindo que a questão do valor era fundamental para o estudo da economia política. Nas poucas ocasiões em que Marx comentou diretamente o assunto, ${ }^{3}$ se referiu à "teoria do valor", e não à teoria do valor-trabalho. Então, como a teoria do valor de Marx se distinguia e como ela diverge da teoria do valor-trabalho?

A resposta é (como de costume) complicada em seus detalhes, mas os seus contornos podem ser reconstruídos a partir da estrutura do primeiro volume de $O$ capital. ${ }^{4}$

Marx começa esse trabalho com um exame da aparência superficial do valor de uso e do valor de troca no ato material da troca de mercadorias e postula a existência do valor (uma relação imaterial, mas objetiva) por trás do aspecto quantitativo do valor de troca. Esse valor é inicialmente considerado um reflexo do trabalho social (abstrato) congelado na forma de mercadorias (capítulo 1). Como uma norma reguladora no mercado, o valor só pode existir, como mostra Marx, quando e onde a troca de mercadorias se tornou "um ato social normal". Essa normalização depende da existência de relações de propriedade privada, de indivíduos jurídicos e de mercados perfeitamente competitivos (capítulo 2). Esse mercado só pode funcionar com o surgimento de formas monetárias (capítulo 3) que facilitam e lubrificam eficientemente as relações de troca, enquanto proporcionam um meio conveniente para armazenar valor. Assim, o dinheiro entra em cena no quadro como uma representação material de valor. $\bigcirc$ valor não pode existir sem sua representação. Nos capítulos de 4 a 6, Marx mostra que, apenas em um sistema no qual o objetivo e objeto da atividade econômica são a produção de mercadorias, a troca se torna um ato social tão necessário quanto normal. É a circulação de dinheiro como capital (capítulo 5) que consolida as condições para a configuração da forma valor característica do capital como norma reguladora. Mas a circulação de capital pressupõe a existência prévia de trabalhado assalariado como uma mercadoria que pode ser comprada e vendida no mercado (capítulo 6). Como o trabalho se tornou tal mercadoria antes da ascensão do capitalismo é o tema da parte 8 de $O$ capital, que lida com a forma primitiva ou original de acumulação.

O conceito de capital como um processo - como valor em movimento - baseado na compra de força de trabalho e de meios de produção está intrinsecamente ligado ao surgimento da forma valor. Uma analogia simples, mas rudimentar, para o argumento de Marx poderia ser:

3 Ver "Notas sobre Adolph Wagner" em Marx (1976). [NA]

4 Muito do que está aqui exposto advém de Harvey (2017). [NA] 
o corpo humano depende, para sua vitalidade, da circulação do sangue, que não pode acontecer fora do corpo humano. Os dois fenômenos são mutuamente constitutivos. A formação de valor também não pode ser entendida fora do processo de circulação que a abriga. A interdependência mútua dentro da totalidade da circulação do capital é o que importa. No caso do capital, no entanto, o processo aparece não apenas como autorreprodutivo (cíclico), mas também como autoexpansivo (a forma espiral da acumulação). Isto é assim porque a busca por lucro e mais-valia impulsionam as trocas de mercadorias, que, por sua vez, promovem e sustentam a forma valor. $\bigcirc$ valor torna-se, assim, uma norma reguladora incorporada na esfera da troca apenas sob as condições de acumulação do capital.

\section{Figura 1 - Produção, reprodução e destruição do homem, da natureza e da cultura}

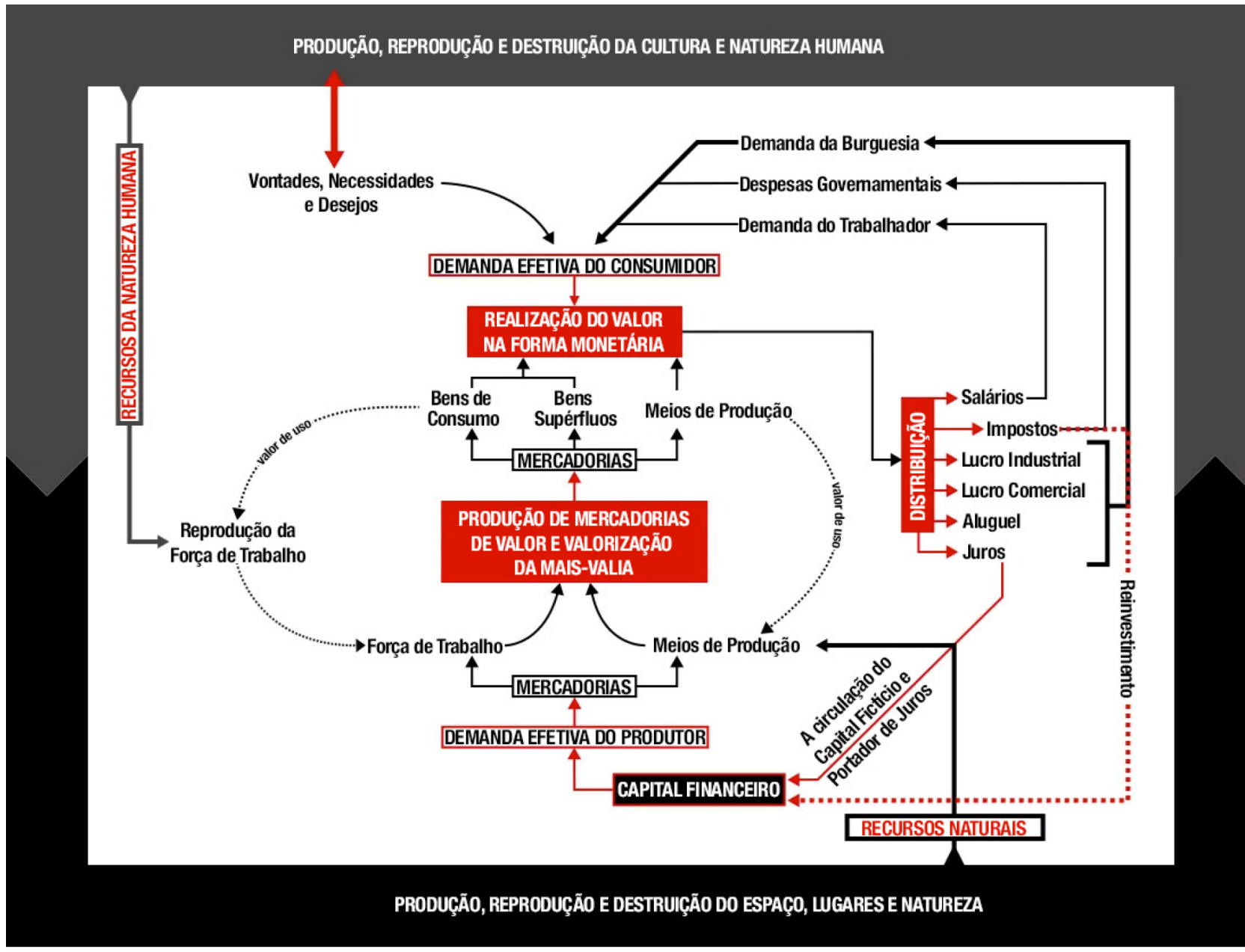

Embora os passos do argumento sejam complicados, Marx parece ter feito pouco mais do que sintetizar e formalizar a teoria do valor-trabalho de Ricardo incorporando-a na totalidade da circulação e acumulação, como mostrado na Figura 1. A sofisticação e elegância do argumento têm seduzido muitos dos seguidores de Marx a pensar que este era o fim da história. Se assim fosse, então muitas das críticas lançadas contra a teoria do valor de Marx seriam justificadas. Mas isso não é o fim. É de fato o começo. A esperança de Ricardo era de que a teoria 
do valor-trabalho forneceria uma base para entender a formação dos preços. É essa esperança que foi implacavelmente esmagada por análises subsequentes. Marx, desde cedo, entendeu que isso era uma esperança impossível, mesmo quando frequentemente cometia deslizes (eu suspeito que por razões táticas), trocando valor por preço em suas apresentações, como se estes fossem basicamente a mesma coisa. Em outros momentos, ele estudou divergências sistemáticas. No volume 1, Marx reconhece que coisas como consciência, honra e terra improdutiva podem ter um preço, mas nenhum valor. No volume 3 de O Capital, ele explora como a equalização da taxa de lucro no mercado levaria as mercadorias a serem trocadas não pelos seus valores, mas de acordo com os chamados "preços de produção".

Mas Marx não estava especialmente interessado na formação de preços. Ele tinha um propósito diferente. Os capítulos 7 até 25, do volume 1, descrevem detalhadamente as consequências para o trabalhador de viver e trabalhar num mundo onde prevalece a lei do valor, constituída pela generalização e normalização da troca no mercado. Essa é a famosa transição, no final do capítulo 6, em que Marx nos convida a sair da esfera da circulação, "um verdadeiro Éden dos direitos inatos do homem", onde "governam como únicas, liberdade, igualdade, propriedade e Bentham". Assim, mergulhamos no "terreno oculto da produção", onde veremos "não só como o capital produz, mas como ele mesmo, o capital, é produzido" (Marx, 2013, p. 250) [NR]. E só aqui também veremos como se forma o valor.

As leis coercitivas da concorrência no mercado forçam os capitalistas individuais a estender o dia de trabalho ao máximo, ameaçando a vida e o bem-estar do trabalhador na ausência de qualquer força restritiva, como uma legislação para limitar a duração da jornada de trabalho (capítulo 10). Nos capítulos subsequentes, essas mesmas leis coercitivas impulsionam o capital na busca por inovações tecnológicas e organizacionais, para mobilizar e se apropriar dos poderes inerentes da divisão do trabalho e cooperação dos trabalhadores, para projetar máquinas e sistemas de manufatura, para estimular os poderes da educação, conhecimento, ciência e tecnologia, tudo em função da busca pela mais-valia relativa. $\bigcirc$ efeito agregado (capítulo 25) é diminuir o status do trabalhador, criar um exército industrial de reserva, impor condições degradantes de trabalho e desespero entre as classes trabalhadoras, e condenar muitos trabalhadores a viverem em condições de reprodução social que são extremamente miseráveis.

É isso que Diane Elson, em seu artigo seminal sobre o assunto, se refere como "a teoria do valor do trabalho". É uma teoria que enfatiza as consequências do valor operando como uma norma reguladora no mercado para a experiência de trabalhadores condenados pela sua situação a trabalhar para o capital. Esses capítulos também explicam por que Bertell Ollman considera a teoria do valor de Marx antes uma teoria da alienação do trabalho na produção do que um fenômeno de mercado (Elson, 1979; Ollman, 1971). [NA]

Mas a produtividade e a intensidade do trabalho estão sempre mudando sob as pressões da concorrência no mercado (como descrito nos últimos capítulos de $O$ capital). Isso significa que a formulação do valor no primeiro capítulo de $O$ capital é revolucionada pelo que vem depois. $\bigcirc$ valor se torna uma ligação interior instável e perpetuamente em evolução (uma relação interna ou dialética) entre o valor definido na esfera da circulação no mercado e o valor como sendo constantemente redefinido por revoluções na esfera da produção. Anteriormente, nas 
Grundrisse (Marx, 2007, p. 690-711), ${ }^{5}$ Marx chegou a especular, no famoso "fragmento sobre as máquinas", que a incorporação do conhecimento humano no capital fixo iria dissolver completamente o significado do valor, a menos que houvesse algumas forças contrárias ou razões para restaurá-lo. ${ }^{6}$ No volume 3 de O capital, Marx traz o impacto das mudanças tecnológicas nos valores que levam à tese sobre a queda da taxa de lucro. A relação contraditória entre o valor definido no mercado e o valor reconstruído por transformações no processo de trabalho é central para o pensamento de Marx.

A cambiante produtividade no trabalho é, evidentemente, um ponto crucial em todas as formas de análise econômica. No caso de Marx, no entanto, não é a produtividade do trabalho físico, enfatizada na política econômica clássica e neoclássica, que conta. É a produtividade do trabalho em relação à produção de mais-valia que importa. Isso coloca a relação interna entre a busca de mais-valia relativa (por meio de inovações tecnológicas e organizacionais) e valores de mercado no centro da teoria do valor de Marx.

Um primeiro corte da teoria do valor de Marx, penso eu, centra-se na constante mudança e na união contraditória entre o que é tradicionalmente referido como a teoria do valor-trabalho na esfera do mercado (como estabelecido nos seis primeiros capítulos de $O$ capital) e a teoria do valor do trabalho na esfera da produção (como analisado nos capítulos 7 a 25 de O capital).

Mas os materiais apresentados no capítulo 25 de $O$ capital sugerem que não é apenas a experiência no processo de trabalho que está em jogo na teoria do valor. Marx descreve as condições de reprodução social de todos aqueles que foram rebaixados à situação de exército industrial de reserva pela ação da lei geral de acumulação do capital (discutido no capítulo 25). Ele cita relatórios oficiais sobre a saúde pública em áreas rurais da Inglaterra (notadamente os elaborados por um certo Dr. Hunter) e outros relatos da vida cotidiana na Irlanda e na Bélgica, juntamente com o relato de Engels na Situação da classe trabalhadora na Inglaterra em 1844. Todos esses relatórios concordavam que as condições de reprodução social nesse segmento da classe trabalhadora eram piores que quaisquer condições conhecidas sob o feudalismo. Terríveis condições de nutrição, habitação, educação, superlotação, relações de gênero e êxodo contínuo foram exacerbadas por políticas punitivas de bem-estar público (mais notadamente nas Leis para os Pobres na Grã-Bretanha). Foi observado nos relatórios o angustiante fato de que a nutrição entre os detentos nas prisões era superior à nutrição das camadas livres empobrecidas (infelizmente, esse ainda é o caso nos EUA). Isso abre o caminho para uma importante extensão da teoria do valor de Marx. As consequências de uma intensificação da competi-

5 Harvey refere-se aos tópicos dos Grundrisse intitulados "Valor do capital fixo e sua força produtiva. Durabilidade do capital fixo, idem [em relação a sua força produtiva]. - As forças sociais, da divisão do trabalho etc. nada custam ao capital. - Diferença das máquinas a esse respeito (economia dos capitalistas no emprego das máquinas). Lucro e mais-valor", "Maquinaria e mais-valor. Recapitulação da teoria da lei do mais-valor em geral", "Proposição entre as condições objetivas da produção. Troca na proporção entre os componentes do capital", "Money y capital fixe: supões certain amount of wealth (Economist). - Proporção entre o capital fixo e o capital circulante. Fiandeiros de algodão (Economist)", "Escravidão e trabalho assalariado (Stueart). Profit upon alienation. Steuart", "Indústria de lã na Inglaterra desde Isabel (Tuckett). Silk-manufacture (same). Ferro, idem. Cotton" e "A origem do trabalho assalariado livre. Vagabundagem. Tuckett", tais itens se encontram na Terceira Seção de seu "esboço" denominado "O Capital que gera frutos. Juros. Lucro (custos de produção etc.)" e são desenvolvidos ao longo das páginas 301 a 330 do volume II da tradução ao espanhol (Marx, 2007) e na tradução ao português (Marx, 2013, p. 641-662). [NR]

6 O chamado "fragmento sobre as máquinas" tem sido amplamente debatido nos últimos anos (Vercellone, 2007). 
ção capitalista no mercado (incluindo a busca pela mais-valia relativa por meio de mudanças na tecnologia) produzem condições deteriorantes de reprodução social das classes trabalhadoras (ou segmentos significativos delas) se não forem aplicadas forças compensatórias ou políticas públicas para neutralizar esses efeitos.

Da mesma forma que a teoria do valor-trabalho é fundamental para as abordagens de Marx sobre valor, surge "uma teoria do valor da reprodução social" como um importante foco para estudo. Essa é a perspectiva que Marx abre nas últimas seções do capítulo 25 do volume 1 de $O$ capital. Esse é o foco das marxistas feministas que trabalharam assiduamente nos últimos 40 anos para construir uma teoria adequada da reprodução social. ${ }^{7}$

Marx (2013, p. 827) cita um relatório oficial sobre as condições de vida da maioria dos trabalhadores na Bélgica que se veem obrigados a "viver em condições mais precárias que os prisioneiros" ${ }^{1}$ nas cadeias. Esses trabalhadores:

[...] recorrem a expedientes cujo segredo apenas o trabalhador conhece: reduzindo suas ração diária; comendo pão de centeio em vez de pão de trigo, comendo pouca carne ou até mesmo nenhuma, fazendo o mesmo com a manteiga e os condimentos, amontoando a família em uma ou duas peças, onde as moças e rapazes dormem juntos, frequentemente sobre o mesmo colchão de palha, economizando no vestuário, na roupa de baixo, nos meios de limpeza, renunciando aos lazeres dominicais, em suma dispondo-se às mais dolorosas privações. Uma vez alcançado esse limite extremo, o aumento mais ínfimo nos preços dos meios de subsistência, um desemprego, uma doença, multiplicam a miséria do trabalhador e o arruínam por completo. As dívidas se acumulam, o crédito é recusado, as roupas, os móveis mais necessários são recolhidos pela casa de penhores e, por fim, a familia solicita sua inscrição na lista dos indigentes (Marx, 2013, 745-746, NR).

Se esse for um resultado típico da ação da lei capitalista da acumulação de valor, então há uma profunda contradição entre as condições de deterioração da reprodução social e as necessidades do capital de perpetuamente expandir o mercado. Como Marx nota no volume 2 de $O$ capital, a verdadeira raiz da crise do capitalismo reside na supressão dos salários e na redução da massa populacional ao status de indigentes. Se não houver mercado, não há valor. As contradições colocadas do ponto de vista da teoria da reprodução social para os valores como percebidos no mercado são múltiplas. Se, por exemplo, não há trabalhadores saudáveis, instruídos, disciplinados e qualificados no exército de reserva, então ele não pode mais desempenhar seu papel.

As relações dialéticas entre processos competitivos de mercado, produção de mais-valia e reprodução social emergem como elementos da formação de valor profundamente contraditórios, bem como mutuamente constitutivos. Essa estrutura de análise oferece uma forma

7 Ver a recente pesquisa e coleção em Bhattacharya (2017). [NA]

8 Entre os vários estudos de K. Marx para a elaboração de $O$ capital, estão os documentos oficiais sobre a situação das classes trabalhadoras na Inglaterra e nos países onde a indústria se desenvolvia de modo dinâmico e, com ela, a penúria dos assalariados. A citação é dos estudos de Edouard Ducpétiaux sobre os trabalhadores de Bruxelas (Bélgica), e o excerto é do livro Orçamentos econômicos das classes trabalhadoras na Bélgica: subsistência, salário, população, de 1850 (Marx, 2013, p. 745). [NR] 
intrigante de preservar especificidades e diferenças no nível teórico da teoria do valor sem abandonar o conceito de totalidade que o capital perpetuamente reconstrói por meio de suas práticas.

Outras modificações, extensões e elaborações da teoria do valor precisam ser consideradas. A relação tensa e contraditória entre a produção e a sua realização se baseia no fato de que o valor depende da existência de vontades, necessidades e desejos apoiados pela capacidade de pagar por algo em uma população de consumidores. Tais vontades, necessidades e desejos estão profundamente enraizados no mundo da reprodução social. Sem eles, como Marx observa no primeiro capítulo de $O$ capital, não há valor. Isso introduz na discussão a ideia de não valor ou antivalor. Isso também significa que a diminuição dos salários para quase nada seria contraproducente para a realização do valor e da mais-valia no mercado. Aumentar os salários para garantir o "consumo racional" do ponto de vista do capital e colonizar a vida cotidiana como um campo para o consumismo são cruciais para a teoria do valor.

Outro conjunto de problemas a ser resolvido na esfera do valor se coloca quando a presunção da concorrência perfeita dá lugar ao monopólio em geral e à concorrência monopolista inerente à organização espacial da circulação do capital. Eu sugeri recentemente, seguindo algumas formulações relevantes de Marx, substituir a ideia comumente aceita de uma única expressão de valor pelo reconhecimento de uma variedade de distintos regimes de valores regionais dentro da economia global.

A forma valor de Marx, eu concluo, não é um princípio imóvel e estável no mundo tumultuado do capital, mas uma métrica instável e em constante mudança, sendo empurrada para cá e para lá pela anarquia das trocas no mercado, pelas transformações revolucionárias das tecnologias e formas organizacionais, pelas novas práticas de reprodução social e massivas transformações nas vontades, necessidades e desejos de toda uma população, expressas pelas culturas da vida cotidiana. Isso está muito além do que Ricardo tinha em mente e é igualmente distante daquela concepção de valor geralmente atribuída a Marx.

\section{Referências}

BHATTACHARYA, T. Teoria da reprodução social: remapeamento de classes, opressão recente. Londres: Pluto Press, 2017.

ELSON, D. A teoria do valor do trabalho. In: (Org.). Valor: a representação do trabalho no capitalismo. Londres: CSE, 1979.

HARVEY, D. Marx's Refusal of the Labour Theory of Value. Reading Marx's Capital with David Harvey, Oxford, 2018. Disponível em: http://davidharvey.org/. Acesso em 10 maio 2018.

Capital e a loucura da razão econômica. London/New York: Profile/Oxford University Press, 2017.

MARX, K. O capital: a crítica da economia política. São Paulo: Boitempo, 2013. Livro I: $\bigcirc$ processo de produção do capital. 
Elementos fundamentales para la crítica de la economía política: Grundrisse/Borrador: 1857-1858. México, DF: Siglo Veintiuno, 2007. v. I-III.

Valor: estudos de Marx. Londres: New Park, 1976.

OLLMAN, B. Alienação. Londres: Cambridge University Press, 1971.

VERCELLONE, C. Da subsunção formal ao intelecto geral: elementos para uma leitura marxista da tese do capitalismo cognitivo. Materialismo Histórico, n. 15, p. 13-36, 2007. 